\title{
RANKING RANGE BASED APPROACH TO MADM UNDER INCOMPLETE CONTEXT AND ITS APPLICATION IN VENTURE INVESTMENT EVALUATION
}

\author{
Yating $\mathrm{LIU}^{1}$, Hengjie ZHANG ${ }^{2}$, Yuzhu $\mathrm{WU}^{3}$, Yucheng DONG ${ }^{3 *}$ \\ ${ }^{1}$ School of Business Administration, Xian University of Technology, Xian 710048, China \\ ${ }^{2}$ Business School, Hohai University, Nanjing 211100, China \\ ${ }^{3}$ Business School, State Key Laboratory of Hydraulics and Mountain River Engineering, \\ Sichuan University, Chengdu 610065, China
}

Received 17 October 2018; accepted 23 February 2019

\begin{abstract}
In real-world Multiple Attribute Decision Making (MADM) problem, the attribute weights information may be unknown or partially known. Several approaches have been suggested to address this kind of incomplete MADM problem. However, these approaches depend on the determination of attribute weights, and setting different attribute weight vectors may result in different ranking positions of alternatives. To deal with this issue, this paper develops a novel MADM approach: the ranking range based MADM approach. In the novel MADM approach, the minimum and maximum ranking positions of every alternative are generated using several optimization models, and the average ranking position of every alternative is produced applying the Monte Carlo simulation method. Then, the minimum, maximum and average ranking positions of the alternative are integrated into a new ranking position of the alternative. This novel approach is capable of dealing with venture investment evaluation problems. However, in the venture investment evaluation process, decision makers will present different risk attitudes. To deal with this issue, two ranking range based MADM approaches with risk attitudes are further designed. A case study and a simulation experiment are presented to show the validity of the proposal.
\end{abstract}

Keywords: multiple attribute decision making, ranking range, incomplete attribute weights, venture investment evaluation, risk attitudes.

JEL Classification: C02, C61, D81.

\section{Introduction}

Multiple Attribute Decision Making (MADM) aims to rank the alternatives based on their evaluation information associated with multiple attributes (Fan, Ma, \& Zhang, 2002; Liu, Dong, Chiclana, Cabrerizo, \& Herrera-Viedma, 2017; Liu, Dong, Liang, Chiclana, \& HerreraViedma, 2018; Wu, Cao, \& Li, 2016; Xu, Wang, \& Merigó, 2014; Yager, 2016), which has

*Corresponding author. E-mail: $y c d o n g @ s c u . e d u . c n$

This is an Open Access article distributed under the terms of the Creative Commons Attribution License (http://creativecommons. org/licenses/by/4.0/), which permits unrestricted use, distribution, and reproduction in any medium, provided the original author and source are credited. 
been used widely in many areas, such as engineering, technology, economy, management and military (Butler, Morrice, \& Mullarkey, 2001; Cid-López, Hornos, Carrasco-Gónzález, \& Herrera-Viedma, 2018; Shevchenko, Ustinovichius, \& Andruškevičius, 2008; Yoon, 1987; Singh, Gupta, \& Mehra, 2017; Zaveckaite, \& Ulbinaite, 2018).

To date, many MADM models have been reported in literature (Yoon \& Hwang, 1981; Zeleny, 1982). Commonly used MADM approaches include: MAUT (Multiple Attribute Utility Theory) (Keeney \& Raiffa, 1976); SAW (Simple Additive Weighting) (Butler et al., 2001); AHP (Analytic Hierarchy Process) (Saaty, 1981, 2013); TOPSIS (Technique for Order Preference by Similarity to an Ideal Solution) (Yoon \& Hwang, 1981; Zeleny, 1982); VIKOR (VlseKriterijumska Optimizacija I Kompromisno Resenje) (Opricovic \& Tzeng, 2004); ELECTRE (ELimination and Choice Expressing REality) (Roy \& Bertier, 1972); PROMETHEE (Preference Ranking Organization Method for Enrichment Evaluation) (Mareschal, Brans, \& Vincke, 1984); TODIM (an acronym in Portuguese of Interactive and Multicriteria Decision Making) (Gomes \& Lima, 1992). Several comprehensive comparative analyses of different MADM models have been conducted in literature. For example, Zanakis, Solomon, Wishart, and Dublish (1998) investigated the performance of different MADM models through a simulation comparison. Karni, Sanchez, and Tummala (1990) analyzed consensus degree of the ranking results obtained by various MADM models, and the results indicated that the AHP, SAW, and ELECTRE rankings do not differ significantly. Wallenius et al. (2008) provided a famous literature review of existing MADM models. Recently, Kabak and Ervural (2017) presented a generic conceptual framework and a classification scheme for MADM models. Meanwhile, the MADM models have been successfully used in various areas, including: resource allocation, plant location and supplier selection, etc. (López, Carrillo, Chavira, \& Noriega, 2017; Opricovic, 1998; Siskos \& Zopounidis, 1987; Zeleny, 1982).

In ideal MADM problems, the weights of the attributes are assumed known precisely. This assumption may be unreasonable due to time pressure or limited expertise in some MADM problems. In the real-world MADM problems, the attribute weights information may be unknown or partially known, which results in incomplete MADM problem. In order to solve incomplete MADM problems, a lot of methods have been proposed. For example, Danielson, Ekenberg, and He (2014) provided an augmenting ordinal method for assessing attribute weights vector, and the obtained attribute weights are adopted in the aggregation process of the MADM. A.T. de Almeida, J.A. de Almeida, Costa, and de Almeida-Filho (2016) proposed the Flexible and Interactive Tradeoff (FITradeoff) method to obtain the attribute weights vector from the partial information on attribute weights. In addition to incomplete attribute weights, the decision making problem with incomplete assessment information has been extensively studied (Cid-López et al., 2018; Cabrerizo, Herrera-Viedma, \& Pedrycz, 2013; Cabrerizo et al., 2017; Li, Rodríguez, Martínez, Dong, \& Herrera, 2018). For example, Wu, Chiclana, and Herrera-Viedma (2015) presented a new trust based consensus model for managing incomplete linguistic assessment information in social network group decision making (GDM).

The existing models for incomplete MADM relied on the setting of attribute weights. A major criticism of these models is that different attribute weights may yield different results, Dong, Liu, Liang, Chiclana, and Herrera-Viedma (2018a) proposed the concept of strategic weight manipulation, in which a decision maker can strategically set the attribute weights to 
obtain his/her desired ranking of alternatives. In order to overcome the shortcomings of the existing MADM models for incomplete MADM problems, we propose a ranking range based MADM approach under incomplete context. The significant characteristic of our approach is that it doesn't depend on the setting of the attribute weights. In this proposed approach, we establish a series of mixed 0-1 linear programming models to obtain the minimum and maximum ranking positions of every alternative from the multiple attribute decision matrix with incomplete attribute weights information. Then, we apply the Monte Carlo simulation method to compute the average ranking position of every alternative. Finally, the minimum, maximum and average ranking positions of every alternative are integrated into a new ranking position of the alternative. A simulation experiment is presented to show the validity of the ranking range based MADM approach.

Venture investment evaluation involving multiple projects (can be seen as the alternatives in the MADM) and multiple evaluation indices (can be seen as the evaluation attribute in the MADM) can be regarded as a MADM problem. The MADM approaches have been widely used in venture investment evaluation system (Aggarwal, Kryscynski, \& Singh, 2015; Barrot, 2016; Hall \& Hofer, 1993; Tyebjee \& Bruno, 1984). In this paper, the proposed ranking range based MADM approach can be used to help the investors select the best investment project(s). However, in a venture investment evaluation problem, the investors often present different risk attitudes. To deal with this kind of MADM, two ranking range based MADM approaches with risk attitudes are further designed. A case study is used to show the practicality of the proposal.

The rest of this paper is organized as follows. Section 1 introduces MADM problem with incomplete attribute weights information. Then, Section 2 proposes the ranking range based approach to deal with the incomplete MADM problem. Following this, Section 3 further develops two ranking range based approaches to cope with MADM problems with risk attitudes, and discusses their applications in venture investment evaluation problems. Subsequently, Section 4 provides a simulation experiment to demonstrate the validity of the proposed approach. Finally, concluding remarks and future research agenda are discussed in last Section.

\section{Incomplete MADM problem}

This section introduces the MADM problem with incomplete attribute weights information.

Let $X=\left\{x_{1}, \ldots, x_{n}\right\}$ be a finite set of alternatives, and $A=\left\{a_{1}, \ldots, a_{m}\right\}$ be a set of attri-

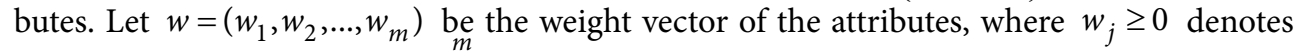
the weight of attribute $a_{j}$ and $\sum_{j=1}^{m} w_{j}=1$. Let $V=\left[v_{i j}\right]_{n \times m}$ be the multiple attribute decision matrix given by the decision maker, where $v_{i j}$ denotes the preference value of the alternative $x_{i} \in X$ associated with attribute $a_{j} \in A$.

Generally, the resolution process of MADM problems includes the following two steps:

\section{(1) Normalization of the multiple attribute decision matrix}

In MADM problems, we can classify the attributes into two categories: benefit and cost attributes. The decision matrix $V=\left[v_{i j}\right]_{n \times m}$ should be normalized into a standardized decision matrix $\bar{V}=\left[\bar{v}_{i j}\right]_{n \times m}$ (Chen, Zhang, \& Dong, 2015; Dong et al., 2018a), where 
if $a_{j} \in A$ is a cost attribute, and

$$
\bar{v}_{i j}=\frac{\max _{i}\left(v_{i j}\right)-v_{i j}}{\max _{i}\left(v_{i j}\right)-\min _{i}\left(v_{i j}\right)},
$$

$$
\bar{v}_{i j}=\frac{v_{i j}-\min _{i}\left(v_{i j}\right)}{\max _{i}\left(v_{i j}\right)-\min _{i}\left(v_{i j}\right)},
$$

if $a_{j} \in A$ is a benefit attribute.

\section{(2) Generating a ranking position of the alternatives}

Let $D_{w}\left(x_{i}\right)$ be the overall evaluation value to alternative $x_{i}$ generated from $\bar{V}=\left[\bar{v}_{i j}\right]_{n \times m}$ and $w=\left(w_{1}, w_{2}, \ldots, w_{m}\right)^{T}$. Many approaches have been reported to produce $D_{w}\left(x_{i}\right)$ (Ishizaka \& Nemery, 2013; Yu, Zhang, Zhong, \& Sun, 2017; B. W. Zhang, Liang, \& G. Q. Zhang, 2018). In particular, the WA (weighted averaging) (Chen, Zhang, \& Dong, 2015; Pérez, Cabrerizo, Alonso, Dong, Chiclana, \& Herrera-Viedma, 2018) and OWA (Ordered weighted averaging) operators (Dong et al., 2018a; Yager, 1988) are used widely in the MADM. Without loss of generality, this paper uses WA and OWA operators to yield $D_{w}\left(x_{i}\right)$ :

$$
\begin{gathered}
D_{w}\left(x_{i}\right)=W A_{w}\left(\bar{v}_{i 1}, \bar{v}_{i 2}, \ldots, \bar{v}_{i m}\right)=\sum_{j=1}^{m} w_{j} \bar{v}_{i j} ; \\
D_{w}\left(x_{i}\right)=O W A_{w}\left(\bar{v}_{i 1}, \bar{v}_{i 2}, \ldots, \bar{v}_{i m}\right)=\sum_{j=1}^{m} w_{j} \bar{v}_{i(j)},
\end{gathered}
$$

where $\bar{v}_{i(j)}$ is the $j$ th largest value in $\left\{\bar{v}_{i 1}, \bar{v}_{i 2}, \ldots, \bar{v}_{i m}\right\}$.

Based on the Eqs (3)-(4), we can obtain the ranking position of the alternative $x_{k}$ as follows:

$$
r_{w}\left(x_{k}\right)=\left|Q_{k, w}\right|+1,
$$

where $Q_{k, w}=\left\{x_{i} \mid D_{w}\left(x_{i}\right)>D_{w}\left(x_{k}\right), \quad i=1,2, \ldots, n\right\}$ denotes the set of the alternatives whose evaluation value(s) is(are) greater than that of the alternative $x_{k}$, and $\left|Q_{k, w}\right|$ signifies the number of alternatives in $Q_{k, w}$ (Dong et al., 2018a).

In ideal MADM problems, the weights of the attributes are assumed known precisely. This assumption may be unreasonable due to time pressure or limited expertise in some practical MADM problems. In the real-world MADM problems, the attribute weights information may be unknown or partially known, which results in incomplete MADM problem. Usually, the known weight information on the attribute can be constructed using the following basic forms:

(i) Weak ranking: $S_{1}=\left\{w_{i} \geq w_{j} \geq 0\right\} \quad(i \neq j)$;

(ii) Strict ranking: $S_{2}=\left\{w_{i}-w_{j} \geq \alpha_{i j}\right\} \quad\left(\alpha_{i j}>0 ; i \neq j\right)$;

(iii) Ranking multiples: $S_{3}=\left\{w_{i} \geq \alpha_{i j} w_{j}\right\} \quad(i \neq j)$;

(iv) Interval form: $S_{4}=\left\{\gamma_{i} \leq w_{i} \leq \gamma_{i}+\varepsilon_{i}\right\} \quad\left(0 \leq \gamma_{i} \leq \gamma_{i}+\varepsilon_{i} \leq 1\right)$;

(v) Ranking differences: $S_{5}=\left\{w_{i}-w_{j} \geq w_{k}-w_{i}\right\} \quad(i \neq j \neq k)$.

In practical, the weights information may consist of above multiple basic forms. In general, we denote $S$ as the set of incomplete attribute weights information. In particular, $S=S_{1} \cup S_{2} \cup S_{3} \cup S_{4} \cup S_{5}$. 
In the following, we use an example to explain the basic forms of the attribute weights information.

Example 1: Let $A=\left\{a_{1}, a_{2}, a_{3}, a_{4}, a_{5}, a_{6}\right\}$ be a set of 6 attributes.

(i) The weights information with strict ranking form may be given by:

$$
S=\left\{\left(w_{1}, w_{2}, \ldots, w_{6}\right)^{T} \mid w_{1}-w_{5} \geq 0.17, w_{2}-w_{3} \geq 0.5\right\}
$$

(ii) The weights information with ranking multiples form can be given by:

$$
S=\left\{\left(w_{1}, w_{2}, \ldots, w_{6}\right)^{T} \mid w_{1} \geq 3 w_{3}, \quad w_{2} \geq 0.5 w_{6} \geq 3 w_{5}\right\}
$$

(iii) The weights information consists of interval and ranking differences forms may be given by:

$$
S=\left\{\left(w_{1}, w_{2}, \ldots, w_{6}\right)^{T} \mid 0.1 \leq w_{4} \leq 0.25, w_{1}-w_{3} \geq w_{4}-w_{2}\right\} .
$$

\section{Ranking range based MADM approach}

In this section, we present a novel MADM approach, namely, the ranking range based MADM approach, to solve the incomplete MADM problem.

\subsection{Ranking range under incomplete attribute weights}

This section introduces the ranking range under incomplete attribute weights.

Let $S$ be as above in section 2. Let $r_{w \in S}\left(x_{h}\right)$ be the ranking of alternative $x_{h}$ generated from $V=\left[v_{i j}\right]_{n \times m}$ and $w=\left(w_{1}, w_{2}, \ldots, w_{m}\right)^{T} \quad(w \in S)$. Naturally, $r_{w \in S}\left(x_{h}\right)$ will change when setting different $w=\left(w_{1}, w_{2}, \ldots, w_{m}\right)^{T} \quad(w \in S)$.

Then, we give the definition of ranking ranges of the alternatives under incomplete attribute weights set $S$, which can be presented as follows.

Definition 1: In MADM problems, we call $R_{w \in S}\left(x_{i}\right)=\left[\underline{r}_{w \in S}\left(x_{i}\right), \bar{r}_{w \in S}\left(x_{i}\right)\right]$ as the ranking range of the alternative $x_{i}$ under incomplete attribute weights set $S$, with $\underline{r}_{w \in S}\left(x_{i}\right)=\min _{w \in S} r_{w}\left(x_{i}\right)$ and $\bar{r}_{w \in S}\left(x_{i}\right)=\max _{w \in S} r_{w}\left(x_{i}\right)$ being the best and worst ranking positions of alternative $x_{i}$, respectively.

In the following, we use an example to help us understand Definition 1.

Example 2: Let $\bar{V}=\left[\bar{v}_{i j}\right]_{5 \times 4}$ be a standardized decision matrix over five alternatives $X=\left\{x_{1}, \ldots, x_{5}\right\}$ and four attributes $A=\left\{a_{1}, \ldots, a_{4}\right\} . \bar{V}$ is provided below:

$$
\bar{V}=\left[\begin{array}{llll}
0.89 & 1 & 0.9 & 0.76 \\
0.74 & 0.59 & 0.8 & 0.79 \\
0.92 & 0.45 & 0.53 & 1 \\
1 & 0.47 & 0.91 & 0.63 \\
0.7 & 0.89 & 1 & 0.85
\end{array}\right] .
$$

(1) When WA (i.e., Eq. (3)) is adopted as the decision model, different ranking positions of alternatives will be generated when setting different $w=\left(w_{1}, \ldots, w_{4}\right)^{T}$. 
For example, (i) we have $r_{w}^{W A}\left(x_{1}\right)=1$ if we set $w=(0.09,0.75,0.03,0.13)^{T}$; (ii) we have $r_{w}^{W A}\left(x_{1}\right)=2$ if we set $w=(0.15,0.2,0.19,0.46)^{T}$; (iii) we have $r_{w}^{W A}\left(x_{1}\right)=3$ if we set $w=(0.2,0.2,0.2,0.6)^{T}$; (iv) we have $r_{w}^{W A}\left(x_{1}\right)=4$ if we set $w=(0.05,0.01,0.04,0.9)^{T}$.

In addition, $r_{w}^{W A}\left(x_{1}\right)=5$ cannot be achieved no matter what the attribute weights vector is. So, the ranking range of alternative $x_{1}$, is $R^{W A}\left(x_{1}\right)=[1,4]$.

Using a similar way, we can obtain the ranking ranges of alternatives $\left\{x_{2}, x_{3}, x_{4}, x_{5}\right\}$, and they are $R^{W A}\left(x_{2}\right)=[3,5], R^{W A}\left(x_{3}\right)=[1,5], R^{W A}\left(x_{4}\right)=[1,5]$, and $R^{W A}\left(x_{5}\right)=[1,5]$.

(2) When OWA (i.e., Eq (4)) is employed as the decision model, the ranking ranges of the five alternatives can also be generated. And they are $R^{O W A}\left(x_{1}\right)=[1,4], R^{O W A}\left(x_{2}\right)=[3,5]$, $R^{O W A}\left(x_{3}\right)=[1,5], R^{O W A}\left(x_{4}\right)=[1,4]$, and $R^{O W A}\left(x_{5}\right)=[1,4]$.

\subsection{The proposed MADM approach}

Based on the ranking range presented in section 3.1, here we present ranking range based MADM approach.

The proposed ranking range based MADM approach is mainly composed of three steps: (i) Generating the best ranking position $\left(\underline{r}_{w \in S}\left(x_{i}\right)\right)$ and worst ranking position $\left(\bar{r}_{w \in S}\left(x_{i}\right)\right)$ of every alternative by solving several mixed 0-1 linear programming models; (ii) Producing the average ranking position of every alternative $\left(\overline{\bar{r}}_{w \in S}\left(x_{i}\right)\right)$ using Monte Carlo simulation method; (iii) Integrating the best, worst and average ranking positions of each alternative into a comprehensive ranking position of the alternative.

In the following, we give the details of the process of the ranking range based MADM approach.

\section{(1) Generating the best and worst ranking positions of alternatives}

In this step, we establish several mixed 0-1 linear programming models to compute the best and worst ranking positions of alternatives.

Let $y_{i} \in\{0,1\}, M$ be a large enough number, and $D\left(x_{i}\right)$ be defined as per Eqs (3) and (4). Then, we can easily obtain the following results.

(1) $x_{i} \succ x_{k}$ if and only if $y_{i}=1$ under the conditions $D\left(x_{i}\right)>D\left(x_{k}\right)-\left(1-y_{i}\right) M$ and $D\left(x_{i}\right) \leq D\left(x_{k}\right)+y_{i} M$.

(2) $x_{i} \precsim x_{k}$ if and only if $y_{i}=0$ under the conditions $D\left(x_{i}\right) \leq D\left(x_{k}\right)+y_{i} M$ and $D\left(x_{i}\right)>D\left(x_{k}\right)-\left(1-y_{i}\right) M$.

Based on the above results, Theorems 1 and 2 to obtain the ranking range $R=\left[\underline{r}\left(x_{k}\right), \bar{r}\left(x_{k}\right)\right]$ of the alternative $x_{k}$ under the WA and OWA operators are presented as follows.

Theorem 1: Let $R_{w \in S}^{W A}\left(x_{k}\right)=\left[\underline{r}_{w \in S}^{W A}\left(x_{k}\right), \bar{r}_{w \in S}^{W A}\left(x_{k}\right)\right]$ be the ranking range of alternative $x_{k}$ under incomplete attribute weights set $S$, when we use the WA operator to compute the decision evaluation function as per Eq. (3). Then,

(1) The best ranking position of alternative $x_{k}$ under incomplete attribute weights set $S$, $\underline{r}_{w \in S}^{W A}\left(x_{k}\right)$ can be computed via the following mixed 0-1 linear programming model (6). 


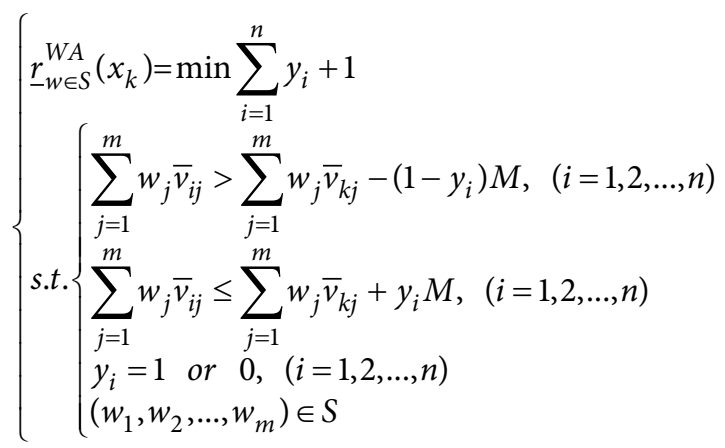

The mixed 0-1 linear programming model (6) is denoted as $P_{1}$ in this paper.

(2) In model (6), replace the objective function (a) by

$$
\bar{r}_{w \in S}^{W A}\left(x_{k}\right)=\max \sum_{i=1}^{n} y_{i}+1 \text {. }
$$

Then, the worst ranking position of alternative $x_{k}$ under incomplete attribute weights set $S, \bar{r}_{w \in S}^{W A}\left(x_{k}\right)$, can be computed via a new mixed 0-1 linear programming model, which we called $P_{2}$ in this paper.

The proof of Theorem 1 is proved in Appendix B.

Theorem 2: Let $R_{w \in S}^{O W A}\left(x_{k}\right)=\left[\underline{r}_{w \in S}^{O W A}\left(x_{k}\right), \bar{r}_{w \in S}^{O W A}\left(x_{k}\right)\right]$ be the ranking range of alternative $x_{k}$ under incomplete attribute weights set $S$, when we use the OWA operator to compute the decision evaluation function as per Eq. (4). Then,

(1) The best ranking position of alternative $x_{k}$ under incomplete attribute weights set $S$, $\underline{r}_{w \in S}^{O W A}\left(x_{k}\right)$ can be computed via the following mixed 0-1 linear programming model (8).

$$
\left\{\begin{array}{l}
\underline{r}_{w \in S}^{O W A}\left(x_{k}\right)=\min \sum_{i=1}^{n} y_{i}+1 \\
\text { s.t. }\left\{\begin{array}{l}
\sum_{j=1}^{m} w_{j} \bar{v}_{i(j)}>\sum_{j=1}^{m} w_{j} \bar{v}_{k(j)}-\left(1-y_{i}\right) M, \quad(i=1,2, \ldots, n) \\
\sum_{j=1}^{m} w_{j} \bar{v}_{i(j)} \leq \sum_{j=1}^{m} w_{j} \bar{v}_{k(j)}+y_{i} M, \quad(i=1,2, \ldots, n) \\
y_{i}=1 \text { or } 0, \quad(i=1,2, \ldots, n) \\
\left(w_{1}, w_{2}, \ldots, w_{m}\right) \in S
\end{array}\right.
\end{array}\right.
$$

The mixed 0-1 linear programming model (8) is denoted as $P_{3}$ in this paper.

(2) In model (8), replace the objective function (a) by

$$
\bar{r}_{w \in S}^{O W A}\left(x_{k}\right)=\max \sum_{i=1}^{n} y_{i}+1 .
$$

Then, the worst ranking position of alternative $x_{k}$ under incomplete attribute weights set $S, \bar{r}_{w \in S}^{O W A}\left(x_{k}\right)$, can be computed via the mixed 0-1 linear programming model, which we called $P_{4}$ in this paper.

The proof of Theorem 2 is proved in Appendix B. 
In the following, we use an example to show the application process of models $P_{1}-P_{4}$.

Example 3: Let $\bar{V}=\left[\bar{v}_{i j}\right]_{5 \times 4}$ be as above in Example 2, and let $S=\left\{\left(w_{1}, w_{2}, w_{3}, w_{4}\right)^{T}\right.$ $\left.\mid w_{3} \geq w_{2} \geq w_{4}\right\}$.

(1) WA based decision model

When taking $\bar{V}$ and $S$ as the inputs of model $P_{1}$, we can obtain that: $\underline{r}_{w \in S}^{W A}\left(x_{1}\right)=1$, $\underline{r}_{w \in S}^{W A}\left(x_{2}\right)=3, \underline{r}_{w \in S}^{W A}\left(x_{3}\right)=2, \underline{r}_{w \in S}^{W A}\left(x_{4}\right)=1$ and $\underline{r}_{w \in S}^{W A}\left(x_{5}\right)=1$.

Moreover, using model $P_{2}$ obtains that: $\bar{r}_{w \in S}^{W A}\left(x_{1}\right)=3, \quad \bar{r}_{w \in S}^{W A}\left(x_{2}\right)=5, \quad \bar{r}_{w \in S}^{W A}\left(x_{3}\right)=5$, $\bar{r}_{w \in S}^{W A}\left(x_{4}\right)=4$ and $\bar{r}_{w \in S}^{W A}\left(x_{5}\right)=5$.

(2) OWA based decision model

Similarly, applying model $P_{3}$ generates that: $\underline{r}_{w \in S}^{O W A}\left(x_{1}\right)=1, \underline{r}_{w \in S}^{O W A}\left(x_{2}\right)=3, \underline{r}_{w \in S}^{O W A}\left(x_{3}\right)=1$, $\underline{r}_{w \in S}^{O W A}\left(x_{4}\right)=1$ and $\underline{r}_{w \in S}^{O W A}\left(x_{5}\right)=1$.

Moreover, applying model $P_{4}$ results in: $\bar{r}_{w \in S}^{O W A}\left(x_{1}\right)=4, \bar{r}_{w \in S}^{O W A}\left(x_{2}\right)=5, \bar{r}_{w \in S}^{O W A}\left(x_{3}\right)=5$, $\bar{r}_{w \in S}^{O W A}\left(x_{4}\right)=4$ and $\bar{r}_{w \in S}^{O W A}\left(x_{5}\right)=4$.

\section{(2) Producing the average ranking positions of alternatives}

In this step, we use Monte Carlo simulation to obtain the average ranking positions of alternatives.

Let $S$ be as introduced in section 2. Let $\overline{\bar{r}}_{w \in S}^{W A}\left(x_{i}\right)$ be the average ranking position of alternative $x_{i}$ under the WA operator with $S$.

The basic idea of generating $\overline{\bar{r}}_{w \in S}^{W A}\left(x_{i}\right)$ is introduced below:

We randomly generate a group of attribute weight vectors from $S$. For each attribute weight vector $w \in S$, we can calculate the ranking positions of alternatives using WA operator. Further, $\overline{\bar{r}}_{w \in S}^{W A}\left(x_{i}\right)$ can be produced by averaging all obtained ranking positions of alternative $x_{i}$.

The detailed process to generate $\overline{\bar{r}}_{w \in S}^{W A}\left(x_{i}\right)$ is described in Appendix C.

Let $\overline{\bar{r}}_{w \in S} \mathrm{OWA}\left(x_{i}\right)$ be the average ranking position of alternative $x_{i}$ under the OWA operator with $S$. The method to generate $\overline{\bar{r}}_{w \in S} O W A\left(x_{i}\right)$ is similar to that of $\overline{\bar{r}}_{w \in S}^{W A}\left(x_{i}\right)$. For space limitation, we omit the process to calculate $\overline{\bar{r}}_{w \in S} O W A\left(x_{i}\right)$.

In the following, we provide an example to show the process to generate $\overline{\bar{r}}_{w \in S}^{W A}\left(x_{i}\right)$ and $\overline{\bar{r}}_{w \in S}^{O W A}\left(x_{i}\right)$.

Example 4: Let $\bar{V}=\left[\bar{v}_{i j}\right]_{5 \times 4}$ and $S=\left\{\left(w_{1}, w_{2}, w_{3}, w_{4}\right)^{T} \mid w_{3} \geq w_{2} \geq w_{4}\right\}$ be as the above in Example 3.

(1) Generating $\overline{\bar{r}}_{w \in S}^{W A}\left(x_{i}\right), \quad(i=1,2, \ldots, 5)$.

Step 1: Generate three attribute weights vectors.

$w_{1}=(0.05,0.25,0.5,0.2)^{T}, w_{2}=(0.55,0.1,0.27,0.08)^{T}, w_{3}=(0.26,0.25,0.27,0.22)^{T}$.

Step 2: Using Eqs (3) and (5) to generate $r_{w_{k}}^{W A}\left(x_{i}\right),(i=1,2,3,4,5 ; k=1,2,3)$. They are provided below:

$$
\begin{aligned}
& \left\{r_{w_{1}}^{W A}\left(x_{1}\right), r_{w_{1}}^{W A}\left(x_{2}\right), r_{w_{1}}^{W A}\left(x_{3}\right), r_{w_{1}}^{W A}\left(x_{4}\right), r_{w_{1}}^{W A}\left(x_{5}\right)\right\}=\{2,4,5,3,1\} ; \\
& \left\{r_{w_{2}}^{W A}\left(x_{1}\right), r_{w_{2}}^{W A}\left(x_{2}\right), r_{w_{2}}^{W A}\left(x_{3}\right), r_{w_{2}}^{W A}\left(x_{4}\right), r_{w_{2}}^{W A}\left(x_{5}\right)\right\}=\{1,5,4,2,3\} ; \\
& \left\{r_{w_{3}}^{W A}\left(x_{1}\right), r_{w_{3}}^{W A}\left(x_{2}\right), r_{w_{3}}^{W A}\left(x_{3}\right), r_{w_{3}}^{W A}\left(x_{4}\right), r_{w_{3}}^{W A}\left(x_{5}\right)\right\}=\{1,4,5,3,2\} .
\end{aligned}
$$


Step 3: Based on $r_{w_{k}}^{W A}\left(x_{i}\right)$, we have $r_{1}=\frac{\left(r_{w_{1}}^{W A}\left(x_{1}\right)+r_{w_{2}}^{W A}\left(x_{1}\right)+r_{w_{3}}^{W A}\left(x_{1}\right)\right)}{3}=\frac{2+1+1}{3}=\frac{4}{3}$, $r_{2}=\frac{4+5+4}{3}=\frac{13}{3}, r_{3}=\frac{5+4+5}{3}=\frac{14}{3}, r_{4}=\frac{3+2+3}{3}=\frac{8}{3}$ and $r_{5}=\frac{1+3+2}{3}=2$.

Further, we obtain that $\overline{\bar{r}}_{w \in S}^{W A}\left(x_{1}\right)=1, \overline{\bar{r}}_{w \in S}^{W A}\left(x_{2}\right)=4, \overline{\bar{r}}_{w \in S}^{W A}\left(x_{3}\right)=5, \overline{\bar{r}}_{w \in S}^{W A}\left(x_{4}\right)=3$ and $\overline{\bar{r}} W \in S\left(x_{5}\right)=2$.

(2) Meanwhile, we can obtain that $\overline{\bar{r}}_{w \in S}^{O W A}\left(x_{1}\right)=1, \overline{\bar{r}}_{w \in S}^{O W A}\left(x_{2}\right)=4, \overline{\bar{r}}_{w \in S}^{O W A}\left(x_{3}\right)=5 \overline{\bar{r}}_{w \in S}^{O W A}\left(x_{4}\right)=3$, and $\overline{\bar{r}}$ OWASA $\left(x_{5}\right)=2$.

\section{(3) Computing the comprehensive ranking positions of alternatives}

In this step, we integrate the best, worst and average rankings of each alternative into a comprehensive ranking position of the alternative.

Let

$$
h\left(x_{i}\right)=\frac{\underline{r}_{w \in S}^{W A}\left(x_{i}\right)+\overline{\bar{r}}_{w \in S}^{W A}\left(x_{i}\right)+\bar{r}_{w \in S}^{W A}\left(x_{i}\right)}{3} .
$$

Obviously, the smaller $h\left(x_{i}\right)$ value indicates the better the alternative $\boldsymbol{x}_{\boldsymbol{i}}$ is.

So, the comprehensive ranking position of alternative $x_{i}$ under WA operator, $r_{w \in S}^{W A}\left(x_{i}\right)$ can be computed as follows:

$$
r_{w \in S}^{W A}\left(x_{i}\right)=g
$$

if $h\left(x_{i}\right)$ is the $g$ th smallest value in $\left\{h\left(x_{1}\right), h\left(x_{2}\right), \ldots, h\left(x_{n}\right)\right\}$.

Using the similar way to calculate $r_{w \in S}^{W A}\left(x_{i}\right)$, the comprehensive ranking position of alternative $x_{i}$ under OWA operator, $r_{w \in S}^{O W A}\left(x_{i}\right)$ can be generated.

In the following, we give an example to show how to compute $r_{w \in S}^{W A}\left(x_{i}\right)$ and $r_{w \in S}^{O W A}\left(x_{i}\right)$.

Example 5: Let $\bar{V}=\left[\bar{v}_{i j}\right]_{5 \times 4}, \quad S=\left\{\left(w_{1}, w_{2}, w_{3}, w_{4}\right)^{T} \mid w_{3} \geq w_{2} \geq w_{4}\right\}, \underline{r}_{w \in S}^{W A}\left(x_{i}\right)$ and $\bar{r}_{w \in S}^{W A}\left(x_{i}\right)$ be as the above in Example 3, and let $\bar{r}_{w \in S}^{W A}\left(x_{i}\right)$ be as the above in Example 4.

(1) Based on Eq (10), we have

$$
\begin{aligned}
& h\left(x_{1}\right)=\frac{\underline{r}_{w \in S}^{W A}\left(x_{1}\right)+\overline{\bar{r}}_{w \in S}^{W A}\left(x_{1}\right)+\bar{r}_{w \in S}^{W A}\left(x_{1}\right)}{3}=\frac{1+\frac{4}{3}+3}{3}=\frac{16}{9}, h\left(x_{2}\right)=\frac{3+\frac{13}{3}+5}{3}=\frac{37}{9}, \\
& h\left(x_{3}\right)=\frac{2+\frac{14}{3}+5}{3}=\frac{35}{9}, h\left(x_{4}\right)=\frac{1+\frac{8}{3}+4}{3}=\frac{23}{9} \text { and } h\left(x_{5}\right)=\frac{1+2+5}{3}=\frac{8}{3} .
\end{aligned}
$$

Clearly, we have $r_{w \in S}^{W A}\left(x_{1}\right)=1, r_{w \in S}^{W A}\left(x_{2}\right)=5, r_{w \in S}^{W A}\left(x_{3}\right)=4, r_{w \in S}^{W A}\left(x_{4}\right)=2$ and $r_{w \in S}^{W A}\left(x_{5}\right)=3$.

(2) Meanwhile, we can obtain that: $h\left(x_{1}\right)=\frac{r_{w \in S}^{O W A}\left(x_{1}\right)+\overline{\bar{r}}_{w \in S}^{O W A}\left(x_{1}\right)+\bar{r}_{w \in S}^{O W A}\left(x_{1}\right)}{3}=\frac{1+1+4}{3}=2$,

$$
\begin{aligned}
& h\left(x_{2}\right)=\frac{3+4+5}{3}=4, h\left(x_{3}\right)=\frac{1+\frac{14}{3}+5}{3}=\frac{32}{9}, h\left(x_{4}\right)=\frac{1+\frac{10}{3}+4}{3}=\frac{25}{9} \text { and } \\
& h\left(x_{5}\right)=\frac{1+2+4}{3}=\frac{7}{3} .
\end{aligned}
$$

Clearly, we have $r_{w \in S}^{O W A}\left(x_{1}\right)=1, \quad r_{w \in S}^{O W A}\left(x_{2}\right)=5, \quad r_{w \in S}^{O W A}\left(x_{3}\right)=4, \quad r_{w \in S}^{O W A}\left(x_{4}\right)=3$ and $r_{w \in S}^{O W A}\left(x_{5}\right)=2$. 


\section{The application of the ranking range based approach in venture investment evaluation with risk attitudes}

In this section, we introduce the venture investment evaluation problem, and construct two ranking range based MADM approaches with risk attitudes to select the best project(s). Meanwhile, the validity of the developed MADM model is demonstrated using a case study.

\subsection{Venture investment evaluation}

Venture investment is an integrative product of technological innovation and capital market, and which plays an important role in the economic development of a country (Fried \& Hisrich, 1994; Tyebjee \& Bruno, 1984). Venture investment evaluation method is often adopted to help the venture capitalists to rank or select the best venture project(s) according to the performances of the projects associated with multiple criteria (or attributes). A lot of methods have been reported in literature for venture investment evaluation problems (Barrot, 2016; Nanda \& Rhodes-Kropf, 2016; Townsend, 2015). For example, Barrot (2016) studied whether and how the contractual horizon of venture capital funds affects investors' investments in innovative firms. Nanda and Rhodes-Kropf (2016) provided a new investment model that reveals the reasons for the correlation between some places, times, as well as industries and a greater degree of experimentation by investors. Townsend (2015) examined how the investors' companies were affected when other companies with the same investors received negative shocks. Additional methods for venture investment evaluation problems can be found in (Aggarwal et al., 2015; Fried \& Hisrich, 1994; Hall \& Hofer, 1993; Tyebjee \& Bruno, 1984).

In general, the evaluation criteria in the venture investment evaluation can be classified into two categories: risk and income criteria. Here, we use $C=\left\{c_{1}, c_{2}, \ldots, c_{m_{1}}\right\}$ and $D=\left\{d_{1}, d_{2}, \ldots, d_{m_{2}}\right\}$ to signify the risk and income criteria, respectively. Let $w^{C}=\left(w_{1}^{C}, w_{2}^{C}, \ldots, w_{m_{1}}^{C}\right)$ be the weight vector of the risk criteria, where $w_{j}^{C} \geq 0$ denotes the weight of attribute $c_{j}$ and $\sum_{j=1}^{m_{1}} w_{j}^{C}=1$. Let $w^{D}=\left(w_{1}^{D}, w_{2}^{D}, \ldots, w_{m_{2}}^{D}\right)$ be the weight vector of the income criteria, where $w_{j}^{D} \geq 0$ denotes the weight of attribute $d_{j}$ and $\sum_{j=1}^{m_{2}} w_{j}^{D}=1$. And, we denote $S^{C}$ and $S^{D}$ as the incomplete attribute weights set of risk and income criteria, respectively.

Let $X=\left\{x_{1}, x_{2}, \ldots, x_{n}\right\}$ be $n$ investment projects. Let $U=\left[u_{i j}\right]_{n \times m_{1}}$ be risk evaluation matrix, where $u_{i j}$ represents the risk evaluation value of project $x_{i}$ associated with $c_{j}, \quad\left(j=1,2, \ldots, m_{1}\right)$. Let $Z=\left[z_{i j}\right]_{n \times m_{2}}$ be income evaluation matrix, where $z_{i j}$ indicates the income evaluation value of alternative $x_{i}$ with respect to $d_{j},\left(j=1,2, \ldots, m_{2}\right)$.

In the venture investment valuation, the investor wants to obtain a best investment project according to $U=\left[u_{i j}\right]_{n \times m_{1}}$ and $Z=\left[z_{i j}\right]_{n \times m_{2}}$. However, different investors have different risk attitudes in the selection of best investment project(s). To deal with this issue, two approaches are developed in the following section. 


\subsection{Ranking range based MADM approaches with risk attitudes}

In this section, two ranking range based MADM approaches with risk attitudes are developed to help investor select the best investment project(s).

Let $U=\left[u_{i j}\right]_{n \times m_{1}}$ be as the above. Let $R^{r i s k}=\left(r_{1}^{r i s k}, r_{2}^{r i s k}, \ldots, r_{n}^{r i s k}\right)^{T}$ be the risk ranking position vectors over projects $X=\left\{x_{1}, x_{2}, \ldots, x_{n}\right\}$ derived from $U$, where $r_{i}^{\text {risk }}$ denotes the risk ranking position of project $x_{i}$. Using models $p_{2}$ or $p_{4}$, we can obtain $\bar{r}_{w \in S}^{W A}\left(x_{i}\right)$ or $\bar{r}_{w \in S}^{O W A}\left(x_{i}\right)$ $(i=1,2, \ldots, n)$ from $U$. We assume that the investor ranks the projects based on $\bar{r}_{w \in S}^{W A}\left(x_{i}\right)$ or $\bar{r}_{w \in S}$ OWA $\left(x_{i}\right) \quad(i=1,2, \ldots, n)$, due to the investor wants to avoid risk to decrease loss from risk. Specifically, $R^{\text {risk }}=\left(r_{1}^{\text {risk }}, r_{2}^{\text {risk }}, \ldots, r_{n}^{\text {risk }}\right)^{T}$ is computed by:

$$
r_{i}^{r i s k}=g
$$

if $\bar{r}_{w \in S}^{W A}\left(x_{i}\right)$ is the gth smallest value in $\left\{\bar{r}_{w \in S}^{W A}\left(x_{1}\right), \ldots, \bar{r}_{w \in S}^{W A}\left(x_{n}\right)\right\}$ (or $\bar{r}_{w \in S}^{O W A}\left(x_{i}\right)$ is the gth smallest value in $\left.\left\{\bar{r}_{w \in S}^{O W A}\left(x_{1}\right), \ldots, \bar{r}_{w \in S}^{O W A}\left(x_{n}\right)\right\}\right)$.

Let $Z=\left[z_{i j}\right]_{n \times m_{2}}$ be as the above. Let $R^{\text {income }}=\left(r_{1}^{\text {income }}, r_{2}^{\text {income }}, \ldots, r_{n}^{\text {income }}\right)^{T}$ be the income ranking position vectors over projects $X=\left\{x_{1}, x_{2}, \ldots, x_{n}\right\}$ derived from $Z$, where $r_{i}^{\text {income }}$ denotes the income ranking position of project $x_{i}$. Here, we consider that $r_{i}^{\text {income }}$ $(i=1,2, \ldots ., n)$ is the comprehensive raking position of $x_{i}$ using the approach presented from section 3.2.

By taking the risk attitudes of investor in the venture investment evaluation process, two methods are designed.

\section{(1) Method I}

In this approach, we consider that the investor wants to select the best project(s) from those projects with acceptable risk level. Let $\overline{r^{r i s k}}$ be a parameter that used to judge whether the risk level of a project is acceptable or not. In particular, if $r_{i}^{r i s k} \leq \overline{r^{r i s k}}$, then the risk level of project $x_{i}$ is acceptable; otherwise, $x_{i}$ is unacceptable. Following this idea, we propose the following model to help the investor select a best project:

$$
\left\{\begin{array}{l}
\operatorname{Min}_{i} r_{i}^{\text {income }} \\
\text { s.t. } r_{i}^{\text {risk }} \leq \overline{r^{\text {risk }}}, \quad i=1,2, \ldots, n .
\end{array}\right.
$$

In model (11), the constraint guarantees that the risk level(s) of the project(s) is acceptable. The objective function finds out the best project from the projects with acceptable risk level.

Example 5: Let $\left\{x_{1}, \ldots, x_{4}\right\}$ be a set of four investment projects. Suppose that $R^{\text {risk }}=\left(r_{1}^{\text {risk }}, r_{2}^{\text {risk }}, r_{3}^{\text {risk }}, r_{4}^{\text {risk }}\right)^{T}=(2,3,4,1)^{T}$ and $R^{\text {income }}=\left(r_{1}^{\text {income }}, r_{2}^{\text {income }}, r_{3}^{\text {income }}, r_{4}^{\text {income }}\right)^{T}=$ $(4,1,2,3)^{T}$.

When setting $\overline{r^{r i s k}}=2$, we find that the risk levels of projects $x_{1}$ and $x_{4}$ are acceptable, due to $r_{1}^{\text {risk }} \leq \overline{r^{r i s k}}$ and $r_{4}^{\text {risk }} \leq \overline{r^{r i s k}}$. For projects $x_{1}$ and $x_{4}$, the best one is $x_{4}$ due to its income level is better. 


\section{(2) Method II}

In this approach, we consider that the investor wants to select the best project(s) from those projects with acceptable income level. Let $\overline{r^{\text {income }}}$ be a parameter that used to judge whether the income level of a project is acceptable or not. In particular, if $r_{i}^{\text {income }} \leq \overline{r^{\text {income }}}$, then the income level of project $x_{i}$ is acceptable; otherwise, $x_{i}$ is unacceptable. Following this idea, we propose the following model to help the investor select a best project:

$$
\left\{\begin{array}{l}
\operatorname{Min}_{i} r_{i}^{\text {risk }} \\
\text { s.t. } r_{i}^{\text {income }} \geq \underline{\text { rincome }^{\text {inco }}}, \quad i=1,2, \ldots, n .
\end{array}\right.
$$

In model (12), the constraint guarantees that the income level(s) of the project(s) is acceptable. The objective function finds out the best project(s) from the projects with acceptable income level.

Example 6: Let $\left\{x_{1}, \ldots, x_{4}\right\}, R^{\text {risk }}=(2,3,4,1)^{T}$ and $R^{\text {income }}=(4,1,2,3)^{T}$ be as above in Example 5.

When setting $\overline{r^{\text {income }}}=2$, we find that the income level of projects $x_{2}$ and $x_{3}$ are acceptable, due to $r_{2}^{\text {income }} \leq \overline{r^{\text {income }}}$ and $r_{3}^{\text {income }} \leq \overline{r^{\text {income }}}$. For projects $x_{2}$ and $x_{3}$, the best one is $x_{2}$ due to its risk level is better.

\subsection{Case study}

In this section, we use a case study of the venture investment evaluation with risk attitudes to show the application process of the proposed approach.

An investor wants to select the best investment project(s) from the following four investment projects: advanced equipment manufacturing $\left(x_{1}\right)$, new energy $\left(x_{2}\right)$, new materials $\left(x_{3}\right)$ and new-energy vehicles $\left(x_{4}\right)$. The risk and income criteria to evaluate the four projects are provided in Tables 1 and 2, respectively.

Table 1. The risk criteria

\begin{tabular}{|l|l|}
\hline \multirow{4}{*}{ Management risk } & $c_{1}$ Commitment of the management team \\
\cline { 2 - 2 } & $c_{2}$ Division of labor and cooperation between management team \\
\cline { 2 - 2 } & $c_{3}$ The ability of managers \\
\hline \multirow{4}{*}{ Technical risk } & $c_{4}$ Technical maturity \\
\hline & $c_{5}$ The reliability of technology \\
\hline & $c_{6}$ Venture capitalists' understanding of technology \\
\hline \multirow{4}{*}{ Production risk } & $c_{7}$ The supply capability of raw material \\
\hline & $c_{8}$ Production capacity \\
\hline \multirow{4}{*}{ Environ risk } & $c_{9}$ Market maturity \\
\hline & $c_{10}$ Familiarity with the marke \\
\hline & $c_{11}$ Potential competition \\
\hline & $c_{12}$ Government policy \\
\hline & $\begin{array}{c}c_{13} \text { Legal environment } \\
c_{14} \text { Exit environment }\end{array}$ \\
\hline
\end{tabular}


Table 2. The income criteria

\begin{tabular}{|c|c|}
\hline \multirow{3}{*}{ Enterprise management level } & $d_{1}$ Enterprises' strategic planning \\
\hline & $d_{2}$ The experience of managers \\
\hline & $d_{3}$ Management philosophy \\
\hline \multirow{4}{*}{ Market attractiveness } & $d_{4}$ Market size \\
\hline & $d_{5}$ Market demand \\
\hline & $d_{6}$ Market potential \\
\hline & $d_{7}$ Competitive advantage in the market \\
\hline \multirow{4}{*}{ Product differentiation } & $d_{8}$ The innovative of products and technologies \\
\hline & $d_{9}$ Level of technology \\
\hline & $d_{10}$ Margins \\
\hline & $d_{11}$ Intellectual property regime \\
\hline \multirow{3}{*}{ Financial evaluation } & $d_{12}$ Liquidity \\
\hline & $d_{13}$ Expected return \\
\hline & $d_{14}$ When break even \\
\hline
\end{tabular}

Moreover, risk evaluation matrix $U=[u]_{4 \times 14}$ and income evaluation matrix $Z=[z]_{4 \times 14}$ are provided in Tables 3 and 4, respectively.

Table 3. The risk evaluation matrix $U=[u]_{4 \times 14}$

\begin{tabular}{|c|c|c|c|c|c|c|c|c|c|c|c|c|c|c|}
\hline$x_{i}$ & $c_{1}$ & $c_{2}$ & $c_{3}$ & $c_{4}$ & $c_{5}$ & $c_{6}$ & $c_{7}$ & $c_{8}$ & $c_{9}$ & $c_{10}$ & $c_{11}$ & $c_{12}$ & $c_{13}$ & $c_{14}$ \\
\hline$x_{1}$ & 0.74 & 0.54 & 0.14 & 0.94 & 0.26 & 0.1 & 0.34 & 0.9 & 0.86 & 0.54 & 0.78 & 0.74 & 0.3 & 0.06 \\
\hline$x_{2}$ & 0.58 & 0.02 & 0.58 & 0.26 & 0.86 & 0.48 & 0.54 & 0.06 & 0.7 & 0.3 & 0.14 & 0.94 & 0.74 & 0.54 \\
\hline$x_{3}$ & 0.26 & 0.34 & 0.06 & 0.58 & 0.58 & 0.14 & 0.66 & 0.94 & 0.18 & 0.06 & 0.86 & 0.5 & 0.98 & 0.98 \\
\hline$x_{4}$ & 0.98 & 0.14 & 0.74 & 0.34 & 0.66 & 0.26 & 0.38 & 0.52 & 0.86 & 0.58 & 0.7 & 0.34 & 0.18 & 0.22 \\
\hline
\end{tabular}

Table 4 . The income evaluation matrix $Z=[z]_{4 \times 14}$

\begin{tabular}{|c|c|c|c|c|c|c|c|c|c|c|c|c|c|c|}
\hline$x_{i}$ & $d_{1}$ & $d_{2}$ & $d_{3}$ & $d_{4}$ & $d_{5}$ & $d_{6}$ & $d_{7}$ & $d_{8}$ & $d_{9}$ & $d_{10}$ & $d_{11}$ & $d_{12}$ & $d_{13}$ & $d_{14}$ \\
\hline$x_{1}$ & 0.66 & 0.22 & 0.86 & 0.18 & 0.62 & 0.98 & 0.9 & 0.1 & 0.34 & 0.86 & 0.98 & 0.66 & 0.7 & 0.66 \\
\hline$x_{2}$ & 0.58 & 0.58 & 0.14 & 0.86 & 0.26 & 0.7 & 0.86 & 0.26 & 0.74 & 0.7 & 0.34 & 0.7 & 0.5 & 0.94 \\
\hline$x_{3}$ & 0.3 & 0.02 & 0.1 & 0.66 & 0.06 & 0.9 & 0.58 & 0.86 & 0.9 & 0.42 & 0.58 & 0.46 & 0.74 & 0.62 \\
\hline$x_{4}$ & 0.14 & 0.7 & 0.34 & 0.42 & 0.46 & 0.34 & 0.06 & 0.46 & 0.18 & 0.98 & 0.42 & 0.9 & 0.06 & 0.1 \\
\hline
\end{tabular}

In this example, we set $S^{C}=\left\{\left(w_{1}^{C}, w_{2}^{C}, \ldots, w_{14}^{C}\right)^{T} \mid w_{1}^{C} \geq w_{2}^{C} \ldots \geq w_{11}^{C}, \quad w_{4}^{C}-w_{9}^{C} \geq w_{6}^{C}-w_{13}^{C}\right.$, $\left.w_{2}^{C} / w_{5}^{C} \leq w_{7}^{C} / w_{11}^{C}\right\}$ and $S^{D}=\left\{\left(w_{1}^{D}, w_{2}^{D}, \ldots, w_{14}^{D}\right)^{T} \mid w_{1}^{D} \geq w_{2}^{D} \geq, \ldots, \geq w_{14}^{D}\right\}$. In the following, we use the proposed approach to help the investor select a best project. In particular, OWA operator is examined in detail.

(1) First, we transform $U=[u]_{4 \times 14}$ and $Z=[z]_{4 \times 14}$ into $\bar{U}=[\bar{u}]_{4 \times 14}$ and $\bar{Z}=[\bar{z}]_{4 \times 14}$ using Eq. (1) and Eq. (2), respectively. $\bar{U}=[\bar{u}]_{4 \times 14}$ and $\bar{Z}=[\bar{z}]_{4 \times 14}$ are listed in Tables 5 and 6, respectively. 
Table 5. The normalized evaluation matrix $\bar{U}=[\bar{u}]_{4 \times 14}$

\begin{tabular}{|c|c|c|c|c|c|c|c|c|c|c|c|c|c|c|}
\hline$x_{i}$ & $c_{1}$ & $c_{2}$ & $c_{3}$ & $c_{4}$ & $c_{5}$ & $c_{6}$ & $c_{7}$ & $c_{8}$ & $c_{9}$ & $c_{10}$ & $c_{11}$ & $c_{12}$ & $c_{13}$ & $c_{14}$ \\
\hline$x_{1}$ & 0.33 & 0 & 0.88 & 0 & 1 & 1 & 1 & 0.05 & 0 & 0.08 & 0.11 & 0.33 & 0.85 & 1 \\
\hline$x_{2}$ & 0.56 & 1 & 0.24 & 1 & 0 & 0 & 0.38 & 1 & 0.24 & 0.54 & 1 & 0 & 0.3 & 0.48 \\
\hline$x_{3}$ & 1 & 0.38 & 1 & 0.53 & 0.47 & 0.89 & 0 & 0 & 1 & 1 & 0 & 0.73 & 0 & 0 \\
\hline$x_{4}$ & 0 & 0.77 & 0 & 0.88 & 0.33 & 0.58 & 0.88 & 0.48 & 0 & 0 & 0.22 & 1 & 1 & 0.83 \\
\hline
\end{tabular}

Table 6. The normalized evaluation matrix $\bar{Z}=[\bar{z}]_{4 \times 14}$

\begin{tabular}{|c|c|c|c|c|c|c|c|c|c|c|c|c|c|c|}
\hline$x_{i}$ & $d_{1}$ & $d_{2}$ & $d_{3}$ & $d_{4}$ & $d_{5}$ & $d_{6}$ & $d_{7}$ & $d_{8}$ & $d_{9}$ & $d_{10}$ & $d_{11}$ & $d_{12}$ & $d_{13}$ & $d_{14}$ \\
\hline$x_{1}$ & 1 & 0.30 & 1 & 0 & 1 & 1 & 1 & 0 & 0.22 & 0.79 & 1 & 0.45 & 0.94 & 0.67 \\
\hline$x_{2}$ & 0.85 & 0.82 & 0.05 & 1 & 0.36 & 0.562 & 0.95 & 0.21 & 0.78 & 0.5 & 0 & 0.55 & 0.65 & 1 \\
\hline$x_{3}$ & 0.31 & 0 & 0 & 0.71 & 0 & 0.88 & 0.62 & 1 & 1 & 0 & 0.38 & 0 & 1 & 0.62 \\
\hline$x_{4}$ & 0 & 1 & 0.32 & 0.35 & 0.71 & 0 & 0 & 0.47 & 0 & 1 & 0.13 & 1 & 0 & 0 \\
\hline
\end{tabular}

(2) Using the method presented in section 4.2, we can obtain $R^{\text {risk }}=(2,2,1,2)^{T}$ from $\bar{U}=[\bar{u}]_{4 \times 14}$. Meanwhile, $R^{\text {income }}=(1,4,2,3)^{T}$ is generated from $\bar{Z}=[\bar{z}]_{4 \times 14}$ using the method proposed in section 4.2 .

(3) Using methods I and II to help the investor select the best project(s).

(i) Method I

When setting $\overline{r^{\text {risk }}}=1$, only the risk level of project $x_{3}$ is acceptable, it is obviously that $x_{3}$ is the best project.

When setting $\overline{r^{r i s k}}=2$, the risk levels for all projects are acceptable, due to $r_{i}^{r i s k} \leq \overline{r^{r i s k}}(i=1,2,3,4)$. For all projects $\left\{x_{1}, \ldots, x_{4}\right\}$, the best one is $x_{1}$ due to its income level is the best.

(ii) Method II

When setting $\overline{r^{\text {income }}}=2$, then income levels of projects $x_{1}$ and $x_{3}$ are acceptable, due to $r_{1}^{\text {income }} \leq \overline{r^{\text {income }}}$ and $r_{3}^{\text {income }} \leq \overline{r^{\text {income }}}$. For projects $x_{1}$ and $x_{3}$, the best one is $x_{3}$ due to its risk level is better.

\section{Simulation analysis}

In this section, we design a simulation experiment to discuss the performance of the proposed model under different aggregation operators.

Let $S$ be as above in section 2. Traditional MADM models assumed that the attribute weights are known precisely. So, when using these models to deal with the incomplete MADM problem, a specific approach is often adopted to generate the complete attribute weights vector from $S$. As a result, the ranking positions of alternatives generated from the traditional MADM models rely on the setting of attribute weights vector.

To date, a lot of MADM models have been reported (Wu \& Liu, 2013; Wu et al., 2016; Wu $\& \mathrm{Xu}, 2016)$. In particular, the MADM models with the WA and OWA operators can be de- 
scribed as Eqs (3) and (4), respectively. Based on Eqs (3) or (4), the ranking positions of the alternatives can be generated. It is noted that the attribute weight vector $w=\left(w_{1}, w_{2}, \ldots, w_{m}\right)^{T}$ needs to be obtained from the incomplete attribute weight information when using Eqs (3) and (4).

Here, we compare the performance of the TM (denotes the traditional MADM model) and NM (denotes the novel MADM model presented in this paper) under WA and OWA operators based on the following criterion. The distance between the ranking positions of alternative $x_{i}$ generated using WA and OWA operators, which can be calculated by

$$
D_{i}=\left|r_{i}^{W A}-r_{i}^{O W A}\right| \text {. }
$$

The main idea of the simulation experiment is that we randomly generate a multiple attribute decision matrix $V=\left[v_{i j}\right]_{n \times m}$. Then, the TM with WA and OWA operators are adopted to yield the ranking positions of alternatives from $V$, respectively. In particular, the weight vectors used in the WA and OWA operators are generated from S. Meanwhile, the ranking positions of alternatives under NM with WA and OWA operators can also be yielded from $V$, respectively. Further, based on Eq. (13), the distances between the ranking positions of alternative $x_{i}$ generated using WA and OWA operators under TM and NM can be calculated, respectively. For simplification, the distances of alternative $x_{i}$ under TM and NM are denoted as $T M D_{i}$ and $N M D_{i}$, respectively.
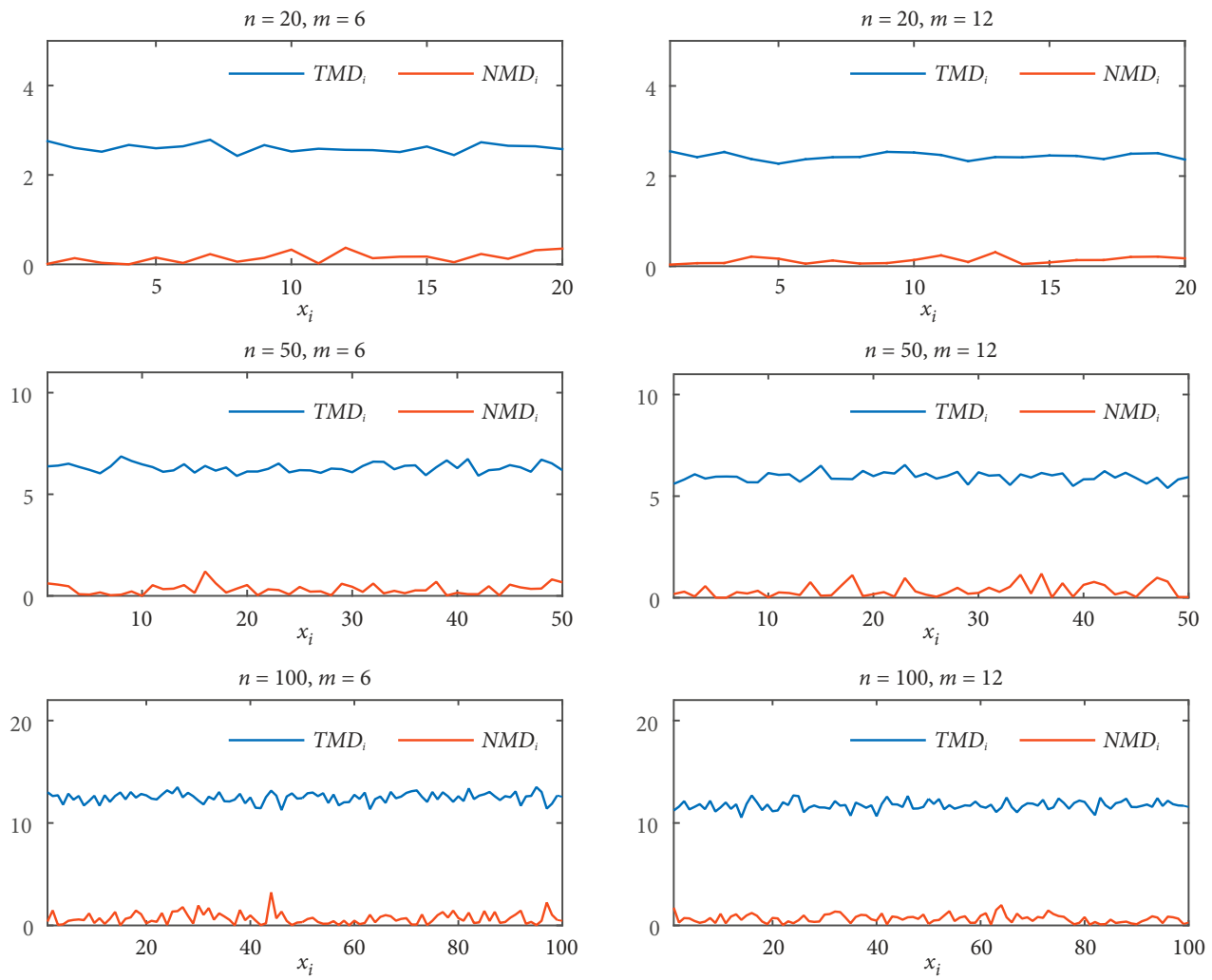

Figure 1. Average values of $T M D_{i}$ and $N M D_{i}(i=1,2, \ldots, n)$ under the simulation method 
To implement above simulation experiment, a simulation method is devised, which is

provided in Appendix D.
$\quad$ In the simulation method, we assume that $S=\left\{\left(w_{1}, \ldots, w_{m}\right)^{T} \mid w_{j} \geq 0, \sum_{j=1}^{m} w_{j}=1\right\}$. Then, we set different values of $n$ and $m$, and run this simulation method 1000 times to obtain average values of $T M D_{i}$ and $N M D_{i}$, which are shown in Figure 1.

From Figure 1, we find that $T M D_{i}>N M D_{i}$ for all alternatives $x_{i}(i=1,2, \ldots ., n)$, under different parameters $n$ and $m$. This finding indicates that the proposed ranking range based MADM approach is insensitive to aggregate operators (WA and OWA operators) compared with existing MADM approaches.

\section{Conclusions}

This paper investigates the incomplete MADM problem, and develops a ranking range MADM approach to cope with this kind of problems. The main contributions of this paper are summarized as follows.

1) A novel MADM approach, namely, ranking range based MADM approach, is presented to address the incomplete MADM problem. This novel approach combines the minimum, maximum, and average (generated using Monte Carlo simulation method) ranking positions of a specific alternative to generate its comprehensive ranking position.

2) Two ranking range based MADM approaches are further developed by taking the risk attitudes of decision makers into account, which are capable of dealing with venture investment evaluation problems.

3) A case study and a simulation experiment are presented to show the validity of the proposed ranking range based MADM approach.

Meanwhile, two interesting research directions are pointed out:

1) Societal and technological trends demand the management of the GDM problem in complex context (e.g., heterogeneous GDM (Cabrerizo et al., 2013; Pérez, Cabrerizo, Alonso, \& Herrera-Viedma, 2014; Zhang, B., Dong, \& Herrera-Viedma, 2019), linguistic GDM (Cabrerizo et al., 2017; Liao, Xu, Herrera-Viedma, \& Herrera, 2018; MorenteMolinera, Kou, Pang, Cabrerizo, \& Herrera-Viedma, 2019; Wu, Li, Chen, \& Dong, 2018; Zhang, H., Dong, Palomares, \& Zhou, 2019), social network GDM (Dong et al., 2018b; Ureña, Kou, Dong, Chiclana, \& Herrera-Viedma, 2019), and large-scale GDM (Dong, Zhao, Zhang, Chiclana, \& Herrera-Viedma, 2018c; Li, Dong, \& Herrera, 2019; Zhang, Guo, \& Martínez, 2017). Moreover, consensus is a key issue in the complex GDM (Dong, Zhang, \& Herrera-Viedma, 2016; Gong, Xu, Zhang, \& Herrera-Viedma, 2015; Sun \& Ma, 2015; B. Zhang, et al., 2018; H. Zhang, Dong, \& Chen, 2018; Zhang, Dong, Chiclana, \& Yu, 2019). So, it would be interesting in any future research to export the ranking range based approach to deal with complex GDM problems, and design a consensus model to support consensus building.

2) Meanwhile, the real-world MADM problems involve not only mathematical aspects but also psychological behaviors of decision maker(s) (see Dong et al., 2018a; Liu et al., 2018; von Winterfeldt \& Edwards, 1986). It would be interesting to study the psychological behaviors of decision maker(s) in the ranking range based MADM approach. 


\section{Acknowledgements}

This work was supported by the grants (Nos.71571124, 71871149 and 71801081) from NSF of China, the grants (Nos. sksyl201705 and 2018hhs-58) from Sichuan University, the grant (No. 18YJC630240) from the Chinese Ministry of Education, the grant (No. BK20180499) from NSF of Jiangsu Province, the grant (No. 2017B07514) from "the Fundamental Research Funds for the Central Universities”, and the grant (No. 105-451119020) from Xi'an University of Technology.

\section{References}

Aggarwal, R., Kryscynski, D., \& Singh, H. (2015). Evaluating venture technical competence in venture capitalist investment decisions. Management Science, 61(11), 2685-2706.

https://doi.org/10.1287/mnsc.2014.2117

Barrot, J. N. (2016). Investor horizon and the life cycle of innovative firms: Evidence from venture capital. Management Science, 7(19), 3021-3043. https://doi.org/10.1287/mnsc.2016.2482

Butler, J., Morrice, D. J., \& Mullarkey, P. W. (2001). A multiple attribute utility theory approach to ranking and selection. Management Science, 47(6), 800-816. https://doi.org/10.1287/mnsc.47.6.800.9812

Cabrerizo, F. J., Al-Hmouz, R., Morfeq, A., Balamash, A. S., Martínez, M. A., \& Herrera-Viedma, E. (2017). Soft consensus measures in group decision making using unbalanced fuzzy linguistic information. Soft Computing, 21(11), 3037-3050. https://doi.org/10.1007/s00500-015-1989-6

Cabrerizo, F. J., Herrera-Viedma, E., \& Pedrycz, W. (2013). A method based on PSO and granular computing of linguistic information to solve group decision making problems defined in heterogeneous contexts. European Journal of Operational Research, 230(3), 624-633.

https://doi.org/10.1016/j.ejor.2013.04.046

Chen, X., Zhang, H. J., \& Dong, Y. C. (2015). The fusion process with heterogeneous preference structures in group decision making: A survey. Information Fusion, 24, 72-83. https://doi.org/10.1016/j.inffus.2014.11.003

Cid-López, A., Hornos, M. J., Carrasco-Gónzález, R. A., \& Herrera-Viedma, E. (2018). Prioritization of the launch of ICT products and services through linguistic multi-criteria decision-making. Technological and Economic Development of Economy, 24(3), 1231-1257. https://doi.org/10.3846/tede.2018.1423

Danielson, M., Ekenberg, L., \& He, Y. (2014). Augmenting ordinal methods of attribute weight approximation. Decision Analysis, 11(1), 21-26. https://doi.org/10.1016/j.ejor.2015.08.058

de Almeida, A. T., de Almeida, J. A., Costa, A. P. C. S., \& de Almeida-Filho, A. T. (2016). A new method for elicitation of criteria weights in additive models: Flexible and interactive tradeoff. European Journal of Operational Research, 250(1), 179-191. https://doi.org/10.1016/j.ejor.2015.08.058

Dong, Y. C., Liu, Y. T., Liang, H. M., Chiclana, F., \& Herrera-Viedma, E. (2018a). Strategic weight manipulation in multiple attribute decision making. Omega, 75, 154-164.

https://doi.org/10.1016/j.omega.2017.02.008

Dong, Y. C., Zha, Q. B., Zhang, H. J., Kou, G., Fujita, H., Chiclana, F., \& Herrera-Viedma, E. (2018b). Consensus reaching in social network group decision making: Research paradigms and challenges. Knowledge-Based Systems, 162, 3-13. https://doi.org/10.1016/j.knosys.2018.06.036

Dong, Y. C., Zhang, H. J., \& Herrera-Viedma, E. (2016). Consensus reaching model in the complex and dynamic MAGDM problem. Knowledge-based Systems, 106, 206-219.

https://doi.org/10.1016/j.knosys.2016.05.046

Dong, Y. C., Zhao, S. H., Zhang, H. J., Chiclana, F., \& Herrera-Viedma, E. (2018c). A self-management mechanism for non-cooperative behaviors in large-scale group consensus reaching processes. IEEE Transactions on Fuzzy Systems, 26(6), 3276-3288. https://doi.org/10.1109/TFUZZ.2018.2818078 
Fan, Z. P., Ma, J., \& Zhang, Q. (2002). An approach to multiple attribute decision making based on fuzzy preference information on alternatives. Fuzzy Sets and Systems, 131(1), 101-106. https://doi.org/10.1016/S0165-0114(01)00258-5

Fried, V. H., \& Hisrich, R. D. (1994). Toward a model of venture capital investment decision making. Financial Management, 23(3), 28-37. Retrieved from https://www.jstor.org/stable/3665619

Gomes, L., \& Lima, M. (1992). TODIM: Basics and application to multicriteria ranking of projects with environmental impacts. Foundations of Computing and Decision Sciences, 16(3-4), 113-27.

Gong, Z. W., Xu, X. X., Zhang, H. H., \& Herrera-Viedma, E. (2015). The consensus models with interval preference opinions and their economic interpretation, Omega, 55, 81-90. https://doi.org/10.1016/j.omega.2015.03.003

Hall, J., \& Hofer, C. W. (1993). Venture capitalists' decision criteria in new venture evaluation. Journal of Business Venturing, 8(1), 25-42. https://doi.org/10.1016/0883-9026(93)90009-T

Ishizaka, A., \& Nemery, P. (2013). Multi-criteria decision analysis: methods and software. John Wiley \& Sons. https://doi.org/10.1002/9781118644898

Kabak, Ö., \& Ervural, B. (2017). Multiple attribute group decision making: A generic conceptual framework and a classification scheme. Knowledge-Based Systems, 123, 13-30. https://doi.org/10.1016/j.knosys.2017.02.011

Karni, R., Sanchez, P., \& Tummala, V. M. R. (1990). A comparative study of multiattribute decision making methodologies. Theory and Decision, 29(3), 203-222. https://doi.org/10.1007/BF00126802

Keeney, R. L., \& Raiffa, H. (1976). Decisions with multiple objectives. New York: John Wiley\&Sons.

Li, C. C., Dong, Y. C., \& Herrera, F. (2019). A consensus model for large-scale linguistic group decision making with a feedback recommendation based on clustered personalized individual semantics and opposing consensus groups. IEEE Transactions on Fuzzy Systems, 27(2), 221-233. https://doi.org/10.1109/TFUZZ.2018.2857720

Li, C. C., Rodríguez, R. M., Martínez, L., Dong, Y. C., \& Herrera, F. (2018). Personalized individual semantics based on consistency in hesitant linguistic group decision making with comparative linguistic expressions. Knowledge-Based Systems, 145, 156-165.

https://doi.org/10.1016/j.knosys.2018.01.011

Liao, H. C., Xu, Z. S., Herrera-Viedma, E., \& Herrera, F. (2018). Hesitant fuzzy linguistic term set and its application in decision making: A state-of-the-art survey. International Journal of Fuzzy Systems, 20(7), 2084-2110. https://doi.org/10.1007/s40815-017-0432-9

Liu, W. Q., Dong, Y. C., Chiclana, F., Cabrerizo, F. J., \& Herrera-Viedma, E. (2017). Group decisionmaking based on heterogeneous preference relations with self-confidence. Fuzzy Optimization and Decision Making, 16(4), 429-447. https://doi.org/10.1007/s10700-016-9254-8

Liu, Y. T., Dong, Y. C., Liang, H. M., Chiclana, F., \& Herrera-Viedma, E. (2018). Multiple attribute strategic weight manipulation with minimum cost in a group decision making context with interval attribute weights information. IEEE Transactions on Systems, Man, and Cybernetics: Systems (in Press). https://doi.org/10.1109/TSMC.2018.2874942

López, J. C. L., Carrillo, P. A. Á., Chavira, D. A. G., \& Noriega, J. J. S. (2017). A web-based group decision support system for multicriteria ranking problems. Operational Research, 17(2), 499-534. https://doi.org/10.1007/s12351-016-0234-0

Mareschal, B., Brans, J. P., \& Vincke, P. (1984). PROMETHEE: A new family of outranking methods in multicriteria analysis. ULB--Universite Libre de Bruxelles.

Morente-Molinera, J. A., Kou, G., Pang, C., Cabrerizo, J., \& Herrera-Viedma, E. (2019). An automatic procedure to create fuzzy ontologies from users' opinions using sentiment analysis procedures and multi-granular fuzzy linguistic modelling methods. Information Sciences, 476, 222-238.

https://doi.org/10.1016/j.ins.2018.10.022 
Nanda, R., \& Rhodes-Kropf, M. (2016). Financing risk and innovation, Management Science, 63(4), 901-918. https://doi.org/10.1287/mnsc.2015.2350

Opricovic, S. (1998). Multicriteria optimization of civil engineering systems. Belgrade: University of Belgrade.

Opricovic, S., \& Tzeng, G. H. (2004). Compromise solution by MCDM methods: A comparative analysis of VIKOR and TOPSIS. European Journal of Operational Research, 156(2), 445-455. https://doi.org/10.1016/S0377-2217(03)00020-1

Pérez, I. J., Cabrerizo, F. J., Alonso, S., \& Herrera-Viedma, E. (2014). A new consensus model for group decision making problems with non homogeneous experts. IEEE Transactions on Systems, Man, and Cybernetics: Systems, 44(4), 494-498. https://doi.org/10.1109/TSMC.2013.2259155

Pérez, I. J., Cabrerizo, F. J., Alonso, S., Dong, Y. C., Chiclana, F., \& Herrera-Viedma, E. (2018). On dynamic consensus processes in group decision making problems. Information Science, 459, 20-35. https://doi.org/10.1016/j.ins.2018.05.017

Roy, B., \& Bertier, B. (1972). La metode ELECTRE II. In Sixieme Conference internationale de rechearche operationelle. Dublin.

Saaty, T. L. (2013). The modern science of multicriteria decision making and its practical applications: the AHP/ANP approach. Operations Research, 61(5), 1101-1118. https://doi.org/10.1287/opre.2013.1197

Saaty, T. L. (1981). The analytic hierarchy process. McGraw-Hill.

Shevchenko, G., Ustinovichius, L., \& Andruškevičius, A. (2008). Multi-attribute analysis of investments risk alternatives in construction. Technological and Economic Development of Economy, 14(3), 428443. https://doi.org/10.3846/1392-8619.2008.14.428-443

Singh, A., Gupta, A., \& Mehra, A. (2017). Energy planning problems with interval-valued 2-tuple linguistic information. Operational Research, 17(3), 821-848.

https://doi.org/10.1007/s12351-016-0245-x

Siskos, J., \& Zopounidis, C. (1987). The evaluation criteria of the venture capital investment activity: An interactive assessment. European Journal of Operational Research, 31(3), 304-313. https://doi.org/10.1016/0377-2217(87)90040-3

Sun, B. Z., \& Ma, W. M. (2015). An approach to consensus measurement of linguistic preference relations in multi-attribute group decision making and application. Omega, 51, 83-92. https://doi.org/10.1016/j.omega.2014.09.006

Townsend, R. R. (2015). Propagation of financial shocks: The case of venture capital. Management Science, 61(11), 2782-2802. https://doi.org/10.1287/mnsc.2014.2110

Tyebjee, T., \& Bruno, A. (1984). A model of venture capitalist investment activity. Management Science, 30(9), 1051-1066. https://doi.org/10.1287/mnsc.30.9.1051

Ureña, R., Kou, G., Dong, Y. C., Chiclana, F., \& Herrera-Viedma, E. (2019). A review on trust propagation and opinion dynamics in social networks and group decision making frameworks. Information Sciences, 478, 461-475. https://doi.org/10.1016/j.ins.2018.11.037

von Winterfeldt, D., \& Edwards, W. (1986). Decisional analysis and behavioral research. New York: Cambridge University Press.

Wallenius, J., Dyer, J. S., Fishburn P. C., Steuer R. E., Zionts S., \& Deb, K. (2008). Multiple criteria decision making, multiattribute utility theory: Recent accomplishments and what lies ahead. Management Science, 54(7), 1336-1349. https://doi.org/10.1287/mnsc.1070.0838

Wu, J., \& Liu, Y. J. (2013). An approach for multiple attribute group decision making problems with interval-valued intuitionistic trapezoidal fuzzy numbers. Computers \& Industrial Engineering, 66(2), 311-324. https://doi.org/10.1016/j.cie.2013.07.001 
Wu, J., Cao, Q. W., \& Li, H. (2016). An approach for MADM problems with interval-valued intuitionistic fuzzy sets based on nonlinear functions. Technological and Economic Development of Economy, 22(3), 336-356. https://doi.org/10.3846/20294913.2014.989931

Wu, J., Chiclana, F., \& Herrera-Viedma, E. (2015). Trust based consensus model for social network in an incomplete linguistic information contex. Applied Soft Computing, 35, 827-839.

https://doi.org/10.1016/j.asoc.2015.02.023

Wu, Y. Z., Li, C. C., Chen, X., \& Dong, Y. C. (2018). Group decision making based on linguistic distributions and hesitant assessments: Maximizing the support degree with an accuracy constraint. Information Fusion, 41, 151-160. https://doi.org/10.1016/j.inffus.2017.08.008

Wu, Z. B., \& Xu, J. P. (2016). Possibility distribution-based approach for MAGDM with hesitant fuzzy linguistic information. IEEE Transactions on Cybernetics, 46(3), 694-705. https://doi.org/10.1109/TCYB.2015.2413894

Xu, Y. J., Wang, H. M., \& Merigó, J. M. (2014). Intuitionistic fuzzy Einstein Choquet integral operator for multiple attribute decision making. Technological and Economic Development of Economy, 20(2), 227-253. https://doi.org/10.3846/20294913.2014.913273

Yager, R. R. (1988). On ordered weighted averaging aggregation operators in multi-criteria decision making. IEEE Transactions on Systems, Man, and Cybernetics, 18(1), 183-190. https://doi.org/10.1109/21.87068

Yager, R. R. (2016). Modeling multi-criteria objective functions using fuzzy measures. Information Fusion, 29, 105-111. https://doi.org/10.1016/j.inffus.2015.07.007

Yoon, K. (1987). A reconciliation among discrete compromise solutions. Journal of Operational Research Society, 38(3), 272-286. https://doi.org/10.1057/jors.1987.44

Yoon, K., \& Hwang, C. L. (1981). Multiple attribute decision making: methods and applications. Berlin: Springer.

Yu, W. Y., Zhang, Z., Zhong, Y. Q., \& Sun, L. L. (2017). Extended TODIM for multi-criteria group decision making based on unbalanced hesitant fuzzy linguistic term sets. Computers \& Industrial Engineering, 114, 316-328. https://doi.org/10.1016/j.cie.2017.10.029

Zanakis, S. H., Solomon, A., Wishart, N., \& Dublish, S. (1998). Multi-attribute decision making: a simulation comparison of select methods. European Journal of Operational Research, 107(3), 507529. https://doi.org/10.1016/S0377-2217(97)00147-1

Zaveckaite, A., \& Ulbinaite, A. (2018). Assessment criteria of project risk management in language translation service companies. Technological and Economic Development of Economy, 24(4), 13231343. https://doi.org/10.3846/20294913.2017.1295287

Zeleny, M. (1982). Multiple criteria decision making. New York: Mc-Graw-Hill.

Zhang, H. J., Dong, Y. C., \& Chen, X. (2018). The 2-rank consensus reaching model in the multigranular linguistic multiple-attribute group decision-making. IEEE Transactions on Systems, Man, and Cybernetics: Systems, 48, 2080-2094. https://doi.org/101109/TSMC20172694429

Zhang, H. J., Dong, Y. C., Palomares, I., \& Zhou, H. W. (2019). Failure mode and effect analysis in a linguistic context: A consensus-based multi-attribute group decision-making approach. IEEE Transactions on Reliability, 68(2), 566-582. https://doi.org/10.1109/TR.2018.2869787

Zhang, H. J., Dong, Y. C., Chiclana, F., \& Yu, S. (2019). Consensus efficiency in group decision making: A comprehensive comparative study and its optimal design. European Journal of Operational Research, 275(2), 580-598. https://doi.org/10.1016/j.ejor.2018.11.052

Zhang, Z., Guo, C. H., \& Martínez, L. (2017). Managing multigranular linguistic distribution assessments in large-scale multiattribute group decision making. IEEE Transactions on Systems, Man, and Cybernetics: Systems, 47(11), 3063-3076. https://doi.org/10.1109/TSMC.2016.2560521 
Zhang, B. W., Liang, H. M., \& Zhang, G. Q. (2018). Reaching a consensus with minimum adjustment in MAGDM with hesitant fuzzy linguistic term sets. Information Fusion, 42, 12-23. https://doi.org/10.1016/j.inffus.2017.08.006

Zhang, B. W., Dong, Y. C., \& Herrera-Viedma, E. (2019). Group decision making with heterogeneous preference structures: An automatic mechanism to support consensus reaching. Group Decision and Negotiation, 28(3), 585-617. https://doi.org/10.1007/s10726-018-09609-y

\section{APPENDIX A}

\section{Notations}

The mainly notation used in this paper is as follows.

$X$ : The set of alternatives;

$A$ : The set of attributes;

$C$ : The set of risk attributes;

$D$ : The set of income attributes;

$V=\left[v_{i j}\right]_{n \times m}$ : Decision matrix;

$\bar{V}=\left[\bar{v}_{i j}\right]_{n \times m}:$ Standardized decision matrix;

$U=\left[u_{i j}\right]_{n \times m}$ : Decision matrix;

$\bar{U}=\left[\bar{u}_{i j}\right]_{n \times m}:$ Standardized decision matrix;

$Z=\left[z_{i j}\right]_{n \times m}$ : Decision matrix;

$\bar{Z}=\left[\bar{z}_{i j}\right]_{n \times m}$ : Standardized decision matrix;

$S:$ The incomplete information of attribute weight set;

$D_{w}\left(x_{i}\right)$ : The evaluation value of the alternative $x_{i}$ under attribute weight $w$;

$\underline{r}_{w \in S}^{r i s k}\left(x_{i}\right)$ : The best risk ranking of the alternative $x_{i}$ under the incomplete attribute weights set $S$;

$\bar{r}_{w \in S}^{r i s k}\left(x_{i}\right)$ : The worst risk ranking of the alternative $x_{i}$ under the incomplete attribute weights set $S$;

$\overline{\bar{r}}_{w \in S}^{r i s k}\left(x_{i}\right)$ : The average risk ranking of the alternative $x_{i}$ under the incomplete attribute weights set $S$;

$r_{i}^{r i s k}$ : The risk ranking of the alternative $x_{i}$;

$\underline{r}_{w \in S}^{\text {income }}\left(x_{i}\right)$ : The best income ranking of the alternative $x_{i}$ under the incomplete attribute weights set $S$;

$\bar{r}_{w \in S}^{\text {income }}\left(x_{i}\right)$ : The worst income ranking of the alternative $x_{i}$ under the incomplete attribute weights set $S$;

$\overline{\bar{r}}_{w \in S}^{\text {income }}\left(x_{i}\right)$ : The average income ranking of the alternative $x_{i}$ under the incomplete attribute weights set $S$;

$r_{i}^{\text {income }}$ : The income ranking of the alternative $x_{i}$. 


\section{APPENDIX B}

\section{Proofs}

\section{Proof of Theorem 1:}

We use two steps to prove Theorem 1.

Step 1: According to result (1), i.e., $x_{i} \succ x_{k}$ if and only if $y_{i}=1$ under the conditions $D\left(x_{i}\right)>D\left(x_{k}\right)-\left(1-y_{i}\right) M$ and $D\left(x_{i}\right) \leq D\left(x_{k}\right)+y_{i} M$, when using WA operator as per Eq. (3), we directly have,

$$
\begin{aligned}
& \underline{r}\left(x_{k}\right)=1+\min \left|\left\{x_{i} \mid D\left(x_{i}\right)>D\left(x_{k}\right), \quad i=1,2, \ldots, n\right\}\right|
\end{aligned}
$$

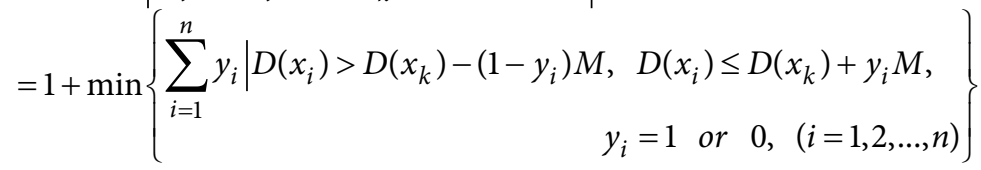

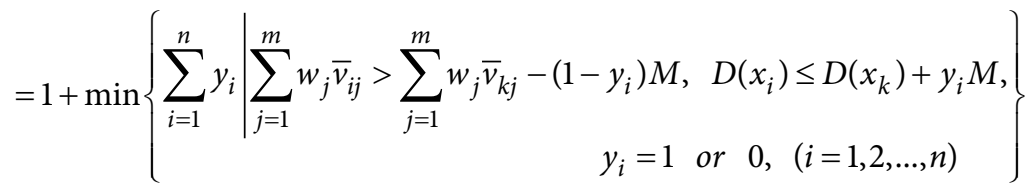

$$
\begin{aligned}
& =1+\min \sum_{i=1}^{n} y_{i}, \quad(i=1,2, \ldots, n) .
\end{aligned}
$$

Step 2: Similar to step 1, we have,

$$
\begin{aligned}
& \bar{r}\left(x_{k}\right)=1+\max \left|\left\{x_{i} \mid D\left(x_{i}\right)>D\left(x_{k}\right)\right\}\right| \\
& \left.\begin{array}{l}
=1+\max \left\{\begin{array}{r}
\sum_{i=1}^{n} y_{i} \mid D\left(x_{i}\right)>D\left(x_{k}\right)-\left(1-y_{i}\right) M, D\left(x_{i}\right) \leq D\left(x_{k}\right)+y_{i} M, \\
y_{i}=1 \text { or } 0,(i=1,2, \ldots, n)
\end{array}\right\} \\
=1+\max \left\{\sum_{i=1}^{n} y_{i} \mid \sum_{j=1}^{m} w_{j} \bar{v}_{i j}>\sum_{j=1}^{m} w_{j} \bar{v}_{k j}-\left(1-y_{i}\right) M, D\left(x_{i}\right) \leq D\left(x_{k}\right)+y_{i} M,\right. \\
y_{i}=1 \text { or } 0,(i=1,2, \ldots, n)
\end{array}\right\} \\
& =1+\max \sum_{i=1}^{n} y_{i}, \quad(i=1,2, \ldots, n),
\end{aligned}
$$

where $M$ is a large enough number.

This completes the proof of Theorem 1 .

\section{Proof of Theorem 2:}

In the process of proving Theorem 1, we only replaced the WA operator $D\left(x_{i}\right)=\sum_{j=1}^{m} w_{j} \bar{v}_{i j}$ and $D\left(x_{k}\right)=\sum_{j=1}^{m} w_{j} \bar{v}_{k j}$ by OWA operator $D\left(x_{i}\right)=\sum_{j=1}^{m} w_{j} \bar{v}_{i(j)}$ and $D\left(x_{k}\right)=\sum_{j=1}^{m} w_{j} \bar{v}_{k(j)}$, re-
spectively.

This completes the proof of Theorem 2 . 


\section{APPENDIX C}

Monte Carlo simulation based approach to obtain $\overline{\bar{r}}_{w \in S}^{W A}\left(x_{i}\right)$

Input: $\bar{V}=\left[\bar{v}_{i j}\right]_{n \times m}$ and $S$.

Output: $\overline{\bar{r}}_{w \in S}^{W A}\left(x_{i}\right), \quad(i=1,2, \ldots, n)$.

Step 1: We randomly generate $N(N \geq 1)$ attribute weights vectors $w_{k}=\left(w_{k, 1}, w_{k, 2}, \ldots, w_{k, m}\right)^{T}$ from $S$, where $\sum_{j=1}^{m} w_{k, j}=1$ and $0 \leq w_{k, j} \leq 1,(k=1,2, \ldots, N)$.

Step 2: Taking $w_{k}=\left(w_{k, 1}, w_{k, 2}, \ldots, w_{k, m}\right)^{T}$ as weight vector of the WA operator (i.e. Eq. (3)), we can obtain the ranking position of alternative $x_{i}$ from $\bar{V}=\left[\bar{v}_{i j}\right]_{n \times m}$, which is denoted as $r_{w_{k}}^{W A}\left(x_{i}\right), \quad(i=1,2, \ldots, m)$.

Step 3: Let $r_{i}=\sum_{k=1}^{N u m} r_{w_{k}}^{W A}\left(x_{i}\right) / N$. Then, we can obtain that $\overline{\bar{r}}_{w \in S}^{W A}\left(x_{i}\right)=g$, if $r_{i}$ is the gth smallest $\left\{r_{1}, r_{2}, \ldots, r_{n}\right\}$. Output $\overline{\bar{r}}_{w \in S}^{W A}\left(x_{i}\right), \quad(i=1,2, \ldots, n)$.

\section{APPENDIX D}

\section{Simulation method used in the simulation analysis}

Input: $n, m$ and $S$.

Output: $T M D_{i}$ and $N M D_{i},(i=1,2, \ldots, n)$

Step 1: Generate a decision matrix $V=\left[v_{i j}\right]_{n \times m}$, where $v_{i j}$ is randomly generated from the interval $[0,1]$.

Step 2: We randomly generate a weight vector from $S$, which is denoted as $w=\left(w_{1}, w_{2}, \ldots, w_{n}\right)^{T}$. Using Eqs (3) and (5) yield $r_{i}^{T M, W A}$ from $V$ and $w$. Meanwhile, applying Eqs (4) and (5) produce $r_{i}^{T M, O W A}$ from $V$ and $w$. Further, we compute $T M D_{i}$ by $T M D_{i}=\left|r_{i}^{T M, W A}-r_{i}^{T M, O W A}\right|$.

Step 3: Using the NM with WA and OWA operators presented in section 3, the ranking positions of alternative $x_{i}$ are generated, respectively, that are $r_{i}^{N M, W A}$ and $r_{i}^{N M, O W A}$. Then, we can obtain $N M D_{i}=\left|r_{i}^{N M, W A}-r_{i}^{N M, O W A}\right|$.

Step 4: Output $T M D_{i}$ and $N M D_{i}, \quad(i=1,2, \ldots, n)$. 